\title{
Habilidades metatextuais: uma intervenção na produção escrita de textos narrativos
}

\author{
Gislaine Gasparin Nobile', https://orcid.org/0000-0001-5463-4779 \\ Sylvia Domingos Barrera1', https://orcid.org/0000-0001-7924-2755
}

\begin{abstract}
Resumo
As habilidades metatextuais constituem um aspecto da metacognição, referindo-se ao conhecimento e controle sobre a organizaçãoestrutural dos diferentes tipos textuais. O objetivo deste estudo foi verificar a eficácia de sessões de intervenção visando ao desenvolvimento das habilidades metatextuais, sobre a produção escrita de histórias eo conhecimento explícito da estrutura narrativa, de alunos do ensino fundamental. Participaram do estudo 97 alunos do $4^{\circ}$ e $5^{\circ}$ ano de uma escola pública, os quais foram divididos em grupo experimental e controle. Os instrumentos utilizados foram produções de texto com tema livre e questionário sobre o conhecimento da estrutura narrativa, aplicados antes e após a intervenção. Os resultados indicaram efeito significativo favorável à intervenção referente ao conhecimento da estrutura narrativa, porém essa melhora se refletiu apenas parcialmente nas produções escritas. Discute-se a diferença entre os processos de conhecimento e controle envolvidos no conceito de metacognição.
\end{abstract}

Palavras-chave: Estrutura do texto; narrativas; metacognição.

\section{The metatextual skills: an intervention in the written production of narrative texts}

\begin{abstract}
The metatextual skills are an aspect of metacognition, referring to knowledge and control over the structural organization of different textual types. The objective of this study was to verify the effectiveness of intervention sessions aiming at the development of metatextual abilities, on the written production of stories and the explicit knowledge of the narrative structure of students of elementary school. The participants were 97 students from the 4th and 5th grade of a public school, which were divided into experimental and control groups. The instruments that have used were the production of texts about free theme and a questionnaire on the knowledge of narrative structure, applied before and after the intervention. The results indicated a significant favorable effect on the intervention concerning the knowledge of the narrative structure, but this improvement was reflected only partially in the written productions. The difference between the knowledge and control processes involved in the concept of metacognition is discussed.
\end{abstract}

Keywords: Text structure; narratives; metacognition.

\section{Habilidades metatextuales: una intervenciónen la producción de escritura de textos narrativos}

\begin{abstract}
Resumen
Las habilidades metatextuales son un aspecto de la metacognición, relativo al conocimiento y control sobre la organización estrutural dedistintos tipos de texto. El objetivo de este estudio fue evaluar la eficacia de una intervención, destinada a desarrollar las habilidades metatextuales,sobre la producción escrita de historias y lo conocimiento de la estructura narrativa de 97 estudiantes de $4^{\circ}$ y $5^{\circ}$ cursos de una escuela pública, los cuales fueron divididos en grupo experimental y control. Como instrumentos se utilizaran la producción de texto con tema libre y cuestionario sobre el conocimiento de la estructura narrativa, aplicados antes y después de la intervención. Los resultados indicaron un efecto significativo favorable a la intervención relacionado con el conocimiento de la estructura narrativa, pero esta mejora se reflejó sólo en parte en las historias escritas. Se discute la diferencia entre los procesos de conocimiento y de control envueltos en el concepto de metacognición.
\end{abstract}

Palabras clave: Estrutura de texto; narrativas; metacognición.

1 Universidade de São Paulo - Ribeirão Preto - SP - Brasil; gislainenobile@yahoo.com.br; sdbarrera@ffclrp.usp.br 


\section{Introdução}

Estudos na área da Psicologia Cognitiva têm evidenciado que a aquisição das estruturas linguísticas, as quais serão manipuladas intencionalmente no ato da escrita, precisam ser dominadas de modo metacognitivo, ou seja, a aprendizagem da leitura e escrita exige o desenvolvimento de uma consciência explícita da linguagem em seus diferentes níveis, o que tem sido referido na literatura pelo termo "habilidades metalinguísticas" (Gombert, 1992; Maluf \& Gombert, 2008). Diferentemente do que ocorre com a aprendizagem da linguagem oral, a qual tem origem em processos biológicos, ativados por meio do contato social e cultural da criança com o seu grupo social, a aprendizagem da linguagem escrita depende de ensino explícito, exigindo um alto nível de abstração, elaboração e controle, principalmente devido ao caráter arbitrário de representação dos sons em sinais gráficos (Maluf \& Gombert, 2008).

Entretanto, apenas o domínio do sistema de escrita alfabético e de suas convenções ortográficas não é suficiente para garantiro seu uso eficientenas situações cotidianas que envolvem práticas de leitura e escrita, principal objetivo dessa aprendizagem. Desse modo, a literatura científica sobre o tema da aprendizagem da escrita tem se preocupado também em estudar os processos cognitivos e linguísticos envolvidos na produção do texto escrito.

Um dos primeiros modelos cognitivos elaborados para explicar os processos e habilidades envolvidos na produção de textos escritos foi proposto por Flower e Hayes (1981). Os autores partem da crítica aos modelos de estágios que consideram a produção escrita como o resultado de um processo linear envolvendo três etapas sucessivas, ou seja, a pré-escrita (planejamento), a escrita (composição) e a reescrita (revisão). No modelo de Flower e Hayes (1981), a escrita é vista como um processo de resolução de problemas, mobilizando muitas habilidades durante a elaboração de um texto, as quais podem ser agrupadas em três principais elementos, os quais refletem as três unidades do modelo: 1) o contexto de produção, o qual envolve, basicamente, o problema retórico que o escritor deve resolver; 2) a memória de longo prazo do escritor, envolvendo o conhecimento armazenado, não somente sobre o conteúdo, mas também sobre o leitor e sobre a composição de textos; e 3) os próprios processos de escrita em si, os quais envolvem os três processos básicos de planejamento, redação e revisão.

Sendo assim, o ato de escrever, além de requerer o domínio do sistema alfabético e ortográfico, das regras gramaticais e de sintaxe, bem como dos conhecimentos sobre pontuação, também depende da organização das ideias, do conhecimento sobre a estrutura dos diferentes tipos de texto, da reflexão sobre o objetivo da escrita, para que tipo de leitor o texto será direcionado, entre outros fatores. Com isso, o escritor, ao escrever um texto, depara-se "... com a necessidade de gerar idéias e de encontrar soluções lingüísticas de forma que o significado se encontre dentro do texto, expresso a partir de sua organização e elementos constituintes que o caracterizam, e com aspectos sintáticos da escrita " (Lins e Silva \& Spinillo, 1998, p.6).

Torna-se relevante, para o aprofundamento do estudo da aprendizagem da escrita, considerar ainda o desenvolvimento das habilidades metalinguísticas e sua relação com a metacognição.Este termo foi introduzido na Psicologia por Flavell, na década de 1970, tendo sido definido como a cognição sobre a cognição, incluindo também qualquer tipo de monitoramento ou atividade autorregulatória sobre o próprio comportamento e/ou processos cognitivos (Flavell,1987).

Segundo Hodges e Nobre (2012), é possível considerar a metalinguagem como um conceito análogo ao conceito de metacognição; nesse âmbito, porém, a análise não diz respeito mais aos próprios processos cognitivos ou as estratégias utilizadas, o objeto de reflexão nas atividades metalinguísticas são os elementos linguísticos. Gombert (1992) considera a metalinguagem como um dos aspectos da metacognição. Assim, se a metalinguagem é parte de uma habilidade metacognitiva mais ampla, considerar a relação entre metalinguagem e alfabetização significa “... reconhecer que o processo de tornar-se alfabetizado demanda do aluno um esforço de reflexão sobre a língua escrita, bem como o monitoramento e controle sobre suas ações cognitivas, ao tentar compreendê-la e produzi-la" (Hodges \& Nobre, 2012, p.93).

Ressalta-se que as habilidades metalinguísticas podem ser consideradas a partir de diversos enfoques, pois é possível refletir e elaborar conhecimentos sobre diferentes aspectos (ou unidades) da linguagem oral, o que nos permite diferenciar entre habilidades metafonológicas, metamorfológicas, metassintáticas, metassemânticas, metatextuais e metapragmáticas (Gombert, 1992).

O termo "metatextual" foi introduzido por Gombert (1992), para se referir a uma habilidade metalinguística na qual a unidade de análise e reflexão é o texto, ou seja, o foco está em sua estrutura, partes constituintes, convenções e marcadores, relacionando ainda essa habilidade ao domínio da coesão e coerência textuais. Segundo o autor, a coerência é a capacidade de controlar as diferentes ideias expressas no texto, mantendo uma compatibilidade entre elas.Sendo assim, um texto se distingue de uma sequência de frases por meio das relações que há entre as diferentes proposições, garantidas dessa forma pela coesão, a qual envolve o domínio dos pronomes anafóricos (referência a algo anteriormente mencionado no texto), artigos definidos e conectores.

Ainda de acordo com a proposta de Gombert (1992), é possível afirmar que, inicialmente, a criança possui um conhecimento epilinguístico, ou seja, não consciente, a respeito de algumas estruturas textuais, decorrente de aprendizagens informais (ou implícitas) sobre o conteúdo, a estrutura e a função de diferentes tipos de texto. Este conhecimento pode variar de acordo com as situações envolvendo a linguagem escrita experimentadas em seu contexto familiar e escolar. Porém, com o ensino formal, sua reflexão sobre o texto tende a aumentar, o que ocorre também com as outras habilidades metalinguísticas, direcionando-se para uma análise intencional, reconhecendo nos textos suas partes 
constituintes (estrutura) e a organização característica dos diferentes tipos textuais.

Segundo Spinillo (2009), nos estudos que abordam as habilidades metatextuais, o texto é visto como unidade de análise, distanciando-se do conteúdo para aproximar-se da forma, por meio da reflexão sobre a sua estrutura e organização. É importante ressaltar que a maioria dos estudos sobre as habilidades metatextuais analisa o texto narrativo, mais especificamente por meio do gênero "história" (Berman, 2008; Borges, 2011; Lins e Silva \& Spinillo, 1998, 2000; Oliveira, 2010; Santos \& Barrera, 2015) embora tenham sido encontrados alguns estudos destinados a outros tipos textuais, como a argumentação (Pinheiro \& Leitão, 2007), ou a produção de resumos (Lopes, 2015).

Ferreira e Spinillo (2003) discutem que a conscientização da organização hierárquica das partes constituintes de um tipo de texto não é imediata, visto que "a capacidade de tomar o texto como objeto de análise é atividade mais complexa que demanda uma ação deliberada sobre a forma e organização do texto" (p.120). Nesse sentido, antes de refletirem intencionalmente sobre o texto, os alunos se utilizam intuitivamente do esquema de produção (conhecimentos implícitos). Além disso,outros fatores influenciam no momento de uma produção textual, como: escolaridade, idade, contato com textos em outros ambientes e situação em que a criança é solicitada a produzir.

Os estudos sobre habilidades metatextuais são relativamente recentes e ainda poucos, como verificado na revisão sistemática da literatura nacional sobre o tema, abrangendo o período de 2006 a 2016, realizada por Silva e Guimarães (2017). As autoras constataram que a reflexão acerca da estrutura do gênero textual, bem como o monitoramente intencional da coesão e coerência, favorecem o desempenho dos alunos na produção escrita de textos, além da necessidade de novas pesquisas que possam examinar outros aspectos que influenciam esse desempenho. De fato, alguns estudos (Ferreira \& Correa, 2008; Oliveira, 2010; Rodrigues \& Vilela, 2012) indicam uma melhora nas produções de texto dos alunos quando essas habilidades são desenvolvidas.

Nesse sentido, os objetivos deste estudo foram: 1) verificar o efeito de sessões de intervenção visando ao desenvolvimento das habilidades metatextuais sobre a produção escrita de histórias com tema livre; 2) verificar o efeito da intervenção sobre o conhecimento explícitoda estrutura dos textos narrativos.

\section{Método}

\section{Participantes}

Participaram deste estudo 97 alunos, sendo 36 do $4^{\circ}$ ano ( $M=8,9$ anos) e 61 do $5^{\circ}$ ano ( $M=10,3$ anos), de uma escola pública, localizada em cidade do interior paulista. Os alunos foram divididos aleatoriamente em grupo controle $(n=50)$ e grupo experimental $(n=47)$.

\section{Instrumentos/Material}

Para a produção livre, os alunos receberam uma foIha elaborada e impressa para ser preenchida com o nome do aluno, ano escolar e linhas na horizontal para a escrita dos textos. Não houve qualquer limite ou restrição de tamanhoou tempopara as produções. Para a avaliação das habilidades metatextuais foi aplicado o Questionário para a Avaliação da Consciência Metatextual (QACM), elaborado em três versões: QACM 1 (pré-teste); QACM 2 (pós-teste 1) e QACM 3 (pós-teste 2). Os questionários foram elaborados com base no instrumento proposto e validado por Santos e Cunha (2011), tendo sido utilizados com o objetivo de identificar os conhecimentos explícitos dos participantes sobre a estrutura do texto narrativo, diferenciando-o de outros gêneros textuais. Houve, portanto, algumas alterações com relação ao instrumento original, a fim de adequá-lo ao gênero textual pesquisado (história), bem como a solicitação das justificativas para as respostas.

\section{Procedimentos}

Após a aprovação do projeto no Comitê de Ética em Pesquisa (sob o número de processo 26634914.0.0000.5407) e na escola, os procedimentos da coleta de dados foram explicados às crianças participantes e, aos pais, foi enviado o Termo de Consentimento Livre e Esclarecido (TCLE). Inicialmente, em sala de aula, os alunos realizaram o pré-teste, que constou de uma produção de texto sobre tema livre, a partir da seguinte instrução: "escrever uma história com tema e assunto livre e criar uma história nova que ninguém havia contado".

Posteriormente os participantes foramseparados, aleatoriamente, em grupo controle (GC) e grupo experimental (GE), compostos por alunos de ambos os anos escolares. Como os grupos ficaram numerosos, houve uma subdivisão em cada um, ou seja, GE1 e GE2, e GC1 e GC2. A intervenção se iniciou com osdois subgrupos experimentais (GE1 e GE2); já os GC1 e GC2 permaneceram em sala de aula desenvolvendo suas atividades curriculares normais.

A escola ofereceu uma sala para a realização das atividades de intervenção. Os participantes do GEpassaram por quatro sessões semanais de intervenção, com duração de uma hora para cada subgrupo,com o objetivo de desenvolver habilidades metatextuais relativas ao conhecimento das especificidades estruturais do gênero "história".

Finalizadas as intervenções com o GE e decorridos 30 dias, houve a aplicação do primeiro pós-teste com os alunos de todos os grupos, GE e GC. Este foi idêntico ao pré-teste, porém com a aplicação do QACM 2 após a segunda produção de texto sobre tema livre. Posteriormente, o GC 
realizou as sessões de intervenção, nas quais foram feitas as mesmas atividades realizadas com o GE.

Após a intervenção com o GC e decorridos 30 dias, houve a aplicação do segundo pós-teste (idêntico ao pós-teste 1, porém com a aplicação do QACM 3) a todos os participantes da pesquisa. Sua aplicação aosalunos do GE teve como objetivo verificar os possíveis efeitos da intervenção a longo prazo.

\section{Sessões de intervenção}

As sessões de intervenção foram planejadas tendo por base o estudo desenvolvido por Ferreira e Spinillo (2003). Na primeira sessão foram lidas e trabalhadas duas histórias, a partir das quais era mostrada e discutida com os alunos a estrutura de organização básica das histórias, explicitando os componentes constituintes da estrutura narrativa: começo (apresentação dos personagens, marcação de tempo e espaço); meio (situação problema) e fim (resolução do problema e desfecho). Posteriormente, como atividade, dois textos impressos foram entregues para que os participantes identificassem as diferentes partes das histórias (começo, meio e fim) e as marcassem com diferentes cores.

Para a segunda sessão, foram utilizadas duas histórias diferentes, apresentadas por meio de sequências de figurinhas embaralhadas.Nessa atividade, a pesquisadora lia a história completa e os alunos eram convidados a ordenar e colar em uma folha, as figurinhas na ordem dos fatos narrados.

Já para a terceira sessão, foram utilizados dois baraIhos de histórias (um de cada vez), compostos por três partes escritas (começo, meio e fim) que, colocadas na sequência correta, formavam uma história completa, tendo os alunos a tarefa de organizar as partes, a fim de compor as histórias. Por fim, para a quarta sessão, os alunos receberam, de forma aleatória, uma de cada vez, três tipos diferentes de histórias: uma contendo somente o começo; a outra o meio; e a outra o final. Eles deveriam reconhecer qual a parte dada e quais partes estavam faltando, para, assim, produzirem (escreverem) as histórias completas.

\section{Análise das produções livre e QACM}

Para as análises das produções de texto livre, tomaram-se como base os critérios adotados nos trabalhos de Spinillo e Martins (1997) e Oliveira (2010). Todavia, algumas adaptações tornaram-se necessárias, buscando-se maior objetividade na atribuição de pontuação aos textos produzidos, em função dos componentes estruturais da narrativa esperados. Verificou-se, assim, se nas três principais partes do texto (início, meio e fim), os componentes estruturais estavam presentes, atribuindo uma pontuação de 0-9 e, mais um ponto era acrescentado para o item denominado "organização", se as ideias ou frases no texto estavam bem articuladas, de acordo com o grau de coerência e coesão deste.
No cenário ou início da história, foram observados e pontuados os seguintes elementos: marco temporal (1 ponto); marco espacial (1 ponto) e personagem (caracterização física ou psicológica, 1 ponto; se somente fosse citado 0,5 ponto). Para o meio ou trama da história: narração de sequência de ações que configurassem um problema com um bom nível de complexidade (3 pontos); desenvolvimento e situação problema pouco elaborados (2 pontos); apenas cita fato(s) que pode $(\mathrm{m})$ ser considerado(s) problemático(s) ou esboço de um problema (1 ponto); ausência de desenvolvimento ou situação problema (0 pontos).

Para o final ou desfecho da história: resolução da situação problema e um fechamento, indicado por marcadores linguísticos como "...e foram felizes para sempre" ou "... e o menino nunca mais desobedeceu sua mãe" (3 pontos); apenas resolução da situação problema (2 pontos); fechamento abrupto, sem resolução da situação problema (1 ponto); sem desfecho (0 pontos). Quanto à organização geral do texto, foram atribuídas as seguintes pontuações: produções textuais com frases bem construídas e ordenadas (1 ponto); produções textuais com frases pouco articuladas ( 0,5 ponto); produções textuais confusas, com problemas na organização das ideias (0 ponto).

As produções foram analisadas por dois juízes independentes, tendo sido calculado o coeficiente de correlação intraclasse $(\mathrm{CCl})$, obtendo-se um nível de concordância, por meio do Coeficiente Alfa de Cronbach ( $\alpha$ ), acima de 0.9 em cada momento da pesquisa (pré-teste, pós-teste 1 e pós-teste 2), o qual indica um excelente nível de concordância. Nos casos onde houve pontuações diferentes entre os juízes, foi utilizada a média aritmética das duas avaliações.

Em relação aos questionários, cada um era composto por cinco questões fechadas (exigindo respostas do tipo sim ou não) sendo solicitada também a justificativa por escrito para cada resposta. Sua estrutura consistia na apresentação de cinco pequenos textos de diferentes gêneros textuais e, para cada um, o aluno deveria responder se aquele texto era ou não uma história, além de justificar a sua resposta. Atribuiu-se um ponto aos acertos nas questões fechadas (total de 5 pontos) e um ponto aos acertos nas justificativas (total de 5 pontos), com valor máximo de 10 pontos. Justificativas pouco elaboradas ou incompletas foram pontuadas com 0,5 ponto.

\section{Resultados}

Os dados foram analisados por meio do programa Statistical Package for the Social Sciences 20.0 (SPSS). Foram analisadas e classificadas 291 produções livres e 291 Questionários. Após a tabulação dos dados no programa SPSS, foi testada a hipótese da normalidade dos resultados, nos três momentosda pesquisa (pré-teste, pós-teste 1 e pós-teste 2), considerando tanto o GE quanto o GC. A partir do teste denormalidade de Kolmogorov-Smirnov e adotando-se um nível de significância de $p \leq 0,05$, concluiu-se que, em relação às produções textuais, é possível manter a hipótese da distribuição normal dos dados, tendo 
Tabela 1. Estatística descritiva do desempenho dos participantes nos instrumentosutilizados nos diferentes momentos do estudo.

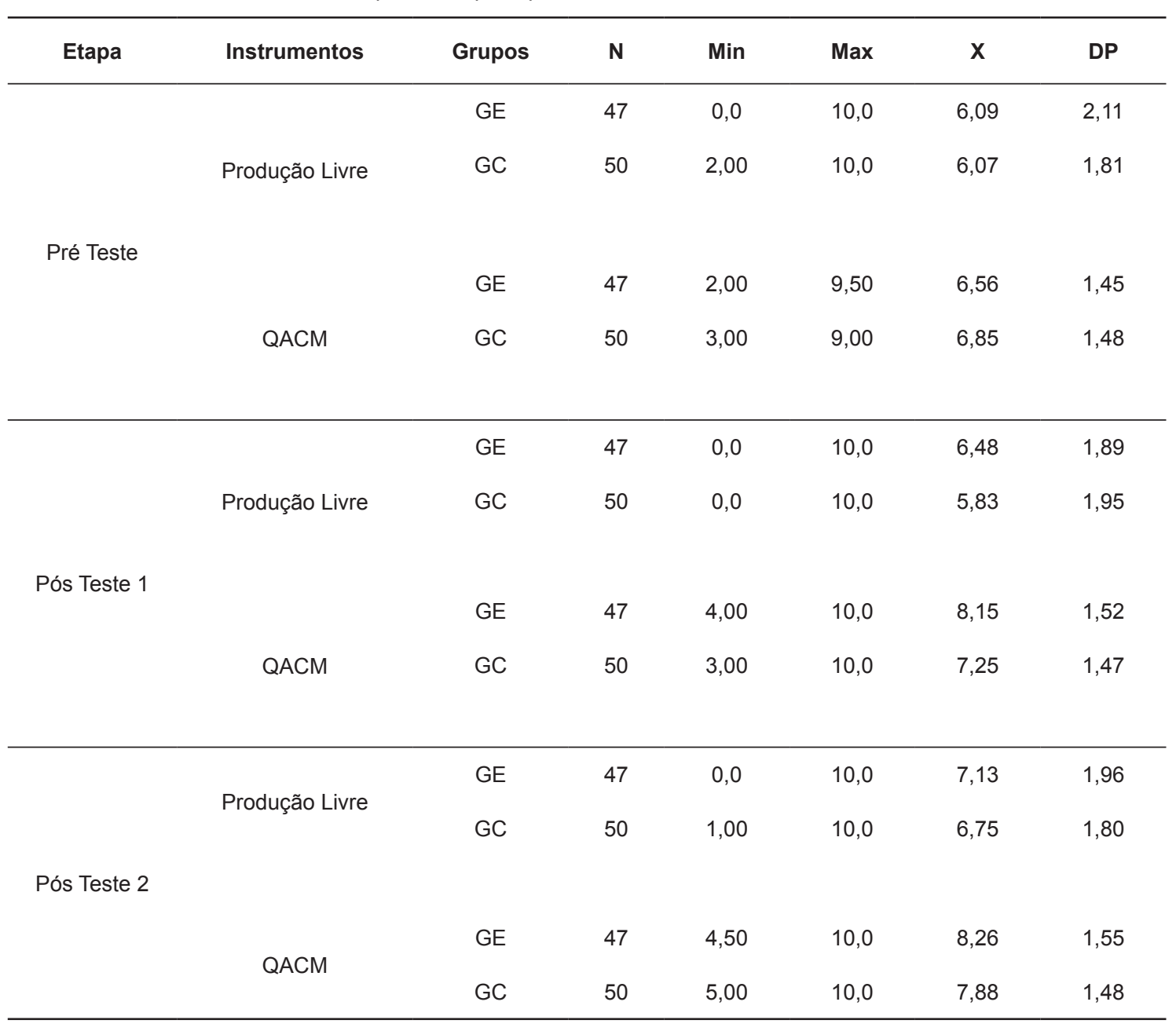

sido utilizados testes paramétricos nas suas análises. Já no caso da maior parte dos resultados do QACM, a hipótese de normalidade dos dados deve ser rejeitada, o que justifica a utilização de testes não paramétricos em suas análises.

De acordo com a Tabela 1, observa-se a menor e a maior pontuação alcançada em cada tarefa (instrumentos), além da pontuação média atingida pelos grupos. Observou-se, para o GE, uma tendência de aumento nas médias das produções livres, considerando as três etapas da pesquisa $(6,09$; $6,48$ e 7,13$)$, como também nos conhecimentos metatextuais avaliados pelos questionários $(6,56 ; 8,15$ e 8,26). Verifica-se no GC, após a realização das sessões de intervenção, ou seja no pós-teste 2 , um aumento da média na produção livre $(6,75)$, considerando que esse grupo no pré-teste obteve uma média de 6,07 e que no pós-teste 1 sua média havia caído $(5,83)$. Como visto no GE, o GC também apresentou aumento das médias nos QACM $(6,85 ; 7,25$ e 7,88).

Posteriormente, realizou-se uma comparação geral entre os grupos, analisando o desempenho dos participantes do GE e GC na produção livre e no QACM em cada momento da pesquisa. Para isso, foi utilizado o teste $t$ para as produções livres, o qual indicou que não houve diferença significativa entre os grupos, visto que os valores de $p$ foram superiores a 0,05 (pré-teste $t=, 052 ; p=, 959$; pós-teste $1, t=1,672 ; p=, 098$; pós-teste $2, t=1,001 ; p=, 319$ ). Essa ausência de diferença no pós-teste 1 parece sugerir que a intervenção não teve o efeito esperado sobre a habilidade de produzir textos narrativos, embora a média do GE tenha superado o GC nessa etapa da avaliação e o valor de $p$ no pós-teste 1 possa ser considerado marginalmente significativo $(p<, 10)$.

Para o QACM utilizou-se o teste de Mann Whitney, teste não paramétrico para a comparação de duas amostras independentes, indicando, no pré-teste, que não houve diferença significativa entre os grupos $(U=-1,029 ; p=, 304)$; no pós-teste 1 , foi observada uma diferença significativa a favor do GE $(U=-3,063 ; p=, 002)$, indicando efeito positivo da intervenção, e após o GC passar pela intervenção, no pós-teste 2 , não foram mais observadas diferenças significativas entre os grupos $(U=-1,368 ; p=, 171)$, mostrando que o GC se equiparou ao GE. Tais resultados sugerem efeitos positivos da intervenção no que se refere ao desenvolvimento das habilidades metatextuais por meio da aplicação dos questionários. 
Comparou-se, também, a evolução dos participantes ao longo da pesquisa, no interior de seus próprios grupos. Em relação às produções textuais, o teste ANOVA para medidas repetidas indicou para o GE uma diferença significativa $\left(F_{(2,92)}\right.$ $=9,337, p=, 000)$. Com o intuito de verificar em qual momento essa diferença ocorre, o post-hoce fetuado a partir do teste de Bonferroni indicou que não houve diferença significativa entre o pré-teste e pós-teste $1(p=, 434)$, embora diferenças significativas tenham sido observadas entre os resultados do pós-teste 1 e pós-teste $2(p=, 025)$ e pré-teste e pós-teste $2(p=, 000)$. Esses resultados indicam um progresso nas habilidades de produzir textos, embora este não possa ser atribuído especificadamente à intervenção, visto a ausência de diferença significativa entre o pré-teste e pós-teste 1.

As análises do GC também indicaram uma diferença significativa $\left(\mathrm{F}_{(2,98)}=5,26, p=, 007\right)$ dos resultados no decorrer da pesquisa, sendo esta observada entre o pós-teste 1 e pós-teste 2 ( $p=, 006)$, momento em que esse grupo passou pela intervenção, sugerindo, portanto, um efeito positivo desta.

A análise dos resultados do QACM foi realizada a partir do teste de Friedman (comparação de mais de duas amostras relacionadas), analisando os três momentos da pesquisa. Para o GE, os resultados indicaram uma diferença significativa $(p=, 000)$, sendo que para refinar a análise dessa diferença foi utilizado o teste de Wilcoxon, com os seguintes pareamentos: QACM pré-teste X QACM pós-teste $1(p=, 000)$; QACM pré-teste X QACM pós-teste 2 ( $p$ $=, 000)$; QACM pós-teste $1 \times$ QACM pós-teste $2(p=, 685)$. Esses resultados indicaram um progresso significativo nas habilidades metatextuais desse grupo entre os momentos pré-teste e pós-teste 1 , o que sugere um efeito positivo da intervenção, já entre os momentos pós-teste 1 e pós-teste 2 não foi observada uma diferença significativa, o que indica que as habilidades se mantiveram constantes.

As análises do QACM do GC, realizadas por meio do teste de Friedman, também indicaram uma diferença significativa $(p=, 002)$ e, a partir dos pareamentos QACM pré-teste X QACM pós-teste $1(p=, 071)$; QACM pré-teste $\mathrm{X}$ QACM pós-teste 2 ( $p=, 000)$; QACM pós-teste $1 \times$ QACM pós-teste 2 ( $p=, 027)$, observou-se que, na comparação entre o pré-teste e pós-teste 1 , não houve uma diferença significativa, já que esse grupo não havia passado por nenhuma intervenção. Nas demais comparações - entre pós-teste 1 e pós-teste 2 e entre pré-teste e pós-teste 2 houve diferenças significativas, o que parece sugerir também um efeito positivo da intervenção sobre as habilidades metatextuais desse grupo de participantes.

\section{Discussão}

O presente estudo teve como objetivo geral verificar a eficácia de sessões de intervenção, visando ao desenvolvimento das habilidades metatextuais, sobre estas habilidades, bem como sobre a escrita de histórias. Análises estatísticas foram efetuadas, comparando-se os resultados do GE e GC por meio da aplicação do teste $t$, o qual indicou que não houve diferenças significativas entre os grupos após o GE ter sido submetido à intervenção (pós-teste 1), embora tenham sido observadas diferenças significativas quando da intervenção postergada do GC. Tais resultados indicam que o efeito positivo esperado, ou seja, produções estruturalmente mais elaboradas dos participantes após as sessões de intervenção, foi apenas parcialmente obtido. . Tais resultados positivos, embora limitados, vão ao encontro daqueles obtidos por Ferreira e Correa (2008), Oliveira (2010) e Rodrigues e Vilela (2012).

Com a aplicação do teste ANOVA para medidas repetidas, observaram-se, tanto no GE quanto no GC, diferenças significativas ao longo do tempo no caso das produções livres. Porém, em relação ao GE, essa diferençanão pode ser atribuída à intervenção, tendo em vista a ausência de diferença na comparação entre os momentos pré-teste e pós-teste 1. Já para o GC, a diferença significativa foi observada entre os momentos pós-teste 1 e pós-teste 2 , fato que coincide com o momento em que esse grupo sofreu a intervenção, sugerindo que esta beneficiou o grupoem suas habilidades de produção de texto livre. Alguns fatores podem ser aventados para explicar esse resultado aparentemente contraditório, entre eles destaca-se o fato de a intervenção com o GC ter sido realizada no segundo semestre letivo, quando os alunos, de modo geral, estavam mais maduros e possivelmente mais competentes para se beneficiarem da intervenção.

É importante ressaltar também que foi encontrado efeito positivo da intervenção sobre as habilidades metatextuais conforme atestam os resultados do QACM, os quais demonstraram que os participantes apresentaram melhoras em seus conhecimentos explícitos sobre os elementos fundamentais para identificação e estruturação do texto narrativo (história), conseguindo diferenciá-lo de outros gêneros textuais, tanto em seu reconhecimento a partir de diversos textos, como nas respostas dadas em suas justificativas.

$\mathrm{Na}$ tarefa de julgamento, realizada por meio da aplicação do questionário para avaliar o desenvolvimento das habilidades metatextuais, as instruções explícitas sobre a estrutura narrativa discutidas na intervenção se fizeram presentes nas respostas dos participantes, principalmente para justificar e diferenciar os diversos tipos de textos, como, por exemplo, responder que determinado texto é uma história, pois apresenta personagens, uma situação problema e uma resolução do problema ou diferenciar a estrutura completa, apontando o começo, meio e fim, mesmo sem explicitar os elementos constituintes de cada parte. Sendo assim e como também discutem Pinheiro e Leitão (2007), é possível que outros fatores, não apenas o desenvolvimento da habilidade metatextual, sejam necessários para a produção eficiente e elaborada de um texto.

De fato, é possível supor, por meio das análises das produções textuais que, mesmo conhecendo explicitamente e diferenciando o esquema narrativo próprio de histórias, outros fatores, como o conteúdo para a produção das histórias, possa ser considerado como tendo influência nos re- 
sultados, já que escrever está relacionado ao conhecimento armazenado na memória de longo prazo, conhecimento esse considerado um dos elementos para a elaboração de um texto, conforme proposto no modelo de Flower e Hayes (1981), no qual o escritor gera, projeta e transforma ideias, a fim de traduzi-las na forma de escrita. Para isso, então, torna-se necessário, além do conhecimento sobre a estrutura textual, um repertório de conteúdo, adquirido, na maioria das vezes, por meio da leitura (diversidade de fontes de informação). Dessa forma, para produzir é preciso ter sobre o que escrever.

Torna-se relevante,também, discutir esses resultados relacionando-os ao conceito de metacogniçãoproposto por Flavell (1987) já que, além do conhecimento sobre o próprio conhecimento, o autor citaa regulação (ou autocontrole) do conhecimento como outro componente da metacognição. De acordo comBrown (1987, citado por Ribeiro, 2003), enquanto o conhecimento é estável e passível de verbalização, o controle desse conhecimento é instável e nem sempre passível de verbalização. Esse fato pode ser observado ao se relacionar o conhecimento às justificativas (respostas) dadas ("verbalizadas") pelos participantes nos questionários e o controle do conhecimento à dificuldade apresentada na utilização desse conhecimento para guiar ou orientar as produções textuais escritas.

De acordo com Ribeiro (2003), a eficácia da aprendizagem não depende somente da idade, experiência e nível intelectual, mas “... também da aquisição de estratégias cognitivas e metacognitivas que possibilitem ao aluno planejar e monitorar o seu desempenho escolar" (p. 115). Com efeito, a distinção realizada por autores que se dedicam ao estudo da metacognição entre conhecimento metacognitivo (sobre si mesmo e a tarefa, por exemplo) e controle metacognitivo, responsável pela automonitoração das estratégias cognitivas a serem realizadas para a execução de uma dada tarefa, podem explicar, ao menos em parte, os resultados obtidos.

De fato, a literatura tem apontado que, além de conhecer a estrutura de um texto (conhecimento metatextual), outros fatores interferem na produção escrita, como a situação na qual a criança é solicitada a produzir (Santos e Barrera, 2015), o contato com textos tanto no ambiente escolar como familiar (Ferreira \&Spinillo, 2003), ter conteúdo para escrever, ou seja, maior experiência com diversos textos e, sobretudo, estar motivada, ter interesse na tarefa. Nesse sentido,ressalta-se a falta de interesse pelas atividades de escrita, observada nos alunos durante a coleta de dados.

Outro fator que pode explicar os resultados encontrados, refere-seàs dificuldades ortográficas apresentadas por muitos participantes. Nesses casos, esforços cognitivos maiores podem ter sido direcionados para a reflexão sobre como grafar determinadas palavras, sobrecarregando a memória de trabalho e dificultando o direcionamento de recursos cognitivos para o controle intencional da estrutura narrativa do texto a ser produzido. Além disso, como apontam Salles e Correa (2014), as dificuldades ortográficas são um fator que explica a falta de motivação de muitos alunos para a produção escrita de textos.

\section{Considerações Finais}

O estudo coloca em evidência a complexidade dos processos cognitivos e metacognitivosenvolvidos na aprendizagem da língua escrita, mais especificamente em relação à produção textual e ao desenvolvimento das habilidades metatextuais. De fato, estas pressupõem uma atividade intencional e reflexiva sobre os componentes estruturais do texto, bem como o domínio da coerência e coesão, associados ao controle e automonitoração de estratégias que permitam a utilização efetiva desses conhecimentos.

Os resultados obtidos, sobretudo com as crianças do GC que participaram da intervenção postergada, sugerem, embora não de modo conclusivo, a possibilidade de que intervenções voltadas para o ensino explícito de habilidades metatextuais possam contribuir, não apenas para o desenvolvimento destas, como também para a melhora no desempenho na produção de textos de alunos do Ensino Fundamental.

Um dos fatores que pode ter limitado o alcance dos resultados obtidos nesta pesquisa, diz respeito ao pequeno número de sessões de intervenção realizadas. Sendo assim, sugere-se a necessidade de novos estudos que incluam mais atividades de produção de texto durante a intervenção (e de reflexões sobre a produção realizada) a fim de consolidar os conhecimentos metatextuais trabalhados. Dessa forma, poderia ser favorecida não apenas a apropriação pelos alunos dos conhecimentos declarativos, mas a sua transposição para conhecimentos executivos e condicionais, relacionados a saber como e quando aplicar um saber ou uma estratégia específica na produção de um texto escrito. Os próprios conceitos de coerência e coesão também poderiam ser abordados durante a intervenção, uma vez que o conhecimento explícito destes também faz parte das habilidades metatextuais.

Por outro lado, a realização deste estudo pode contribuir com pesquisas posteriores, que tentem neutralizar de forma mais adequada as variáveis intervenientes observadas, tais como a falta de motivação e de domínio ortográfico dos participantes, já que este é, até o momento, um dos poucos estudos brasileiros que trabalha com o desenvolvimentos das habilidades metatextuais, utilizando delineamento experimental para verificar o papel destas habilidades na produção escrita de textos.

\section{Referências}

Berman, R. A. (2008). The psycholinguistics of developing text construction. Journal of Child Language, 35(4), 735-771.

Borges, S. M. M. (2011). A estrutura da narrativa escrita, em crianças com diferentes línguas maternas e a mesma língua de escolarização. Dissertação de Mestrado, Escola Superior de Educação de Lisboa, Instituto Politécnico de Lisboa, Lisboa.

Ferreira, A. L.; Spinillo, A. G. (2003). Desenvolvendo a habilidade 
de produção de textos em crianças a partir da consciência metatextual. In: Maluf, M. R. (Org.), Metalinguagem e aquisição da escrita: contribuições da pesquisa para a prática da alfabetização (pp. 119-148). São Paulo: Casa do Psicólogo.

Ferreira, S. P.; Correa, J. (2008). A influência de diferentes contextos de intervenção na escrita de histórias por crianças. Estudos de Psicologia, 25(4), 547-555.

Flavell, J. (1987). Speculations about the nature and development of metacognition. In: Weinert, F.; Kluwe,R. (Orgs.), Metacognition, motivation, and understanding (pp. 21-29). Hillsdale, NJ: Lawrence Erlbaum.

Flower, L.; Hayes, J. R. (1981). A Cognitive Process Theory of Writing. College Composition and Communication, 32(4), 365-387.

Gombert, J. E. (1992). Metalinguistic development.Harvester: Wheatsheaf.

Hodges, L. D.; Nobre, A. P. (2012). Processos cognitivos, metacognitivos e metalinguísticos na aquisição da leitura e escrita. Revista Teoria e Prática da Educação, 15(3), 85-97.

Lins e Silva, M. E.; Spinillo, A. G. (1998). Uma análise comparativa da escrita de histórias pelos alunos de escolas públicas e particulares. Revista Brasileira de Estudos Pedagógicos, 193(79), 6-16.

Lins e Silva, M. E.;Spinillo, A. G. (2000). A Influência de Diferentes Situações de Produção na Escrita de Histórias. Psicologia: Reflexão e Crítica, 13(3), 337-350.

Lopes, M. M. (2015). Consciência Metatextual, compreensão leitora e resumo de histórias - possíveis relações em uma perspectiva psicolinguística. Tese de Doutorado, Faculdade de Letras, Pontifícia Universidade Católica do Rio Grande do Sul, Porto Alegre.

Maluf, M. R.; Gombert, J. E. (2008).Habilidades implícitas e controle cognitivo na aprendizagem da linguagem escrita. In: Maluf, M. R.;
Guimarães, S. R. K. (Orgs.), Desenvolvimento da Linguagem Oral e Escrita (pp.123-135). Curitiba: Editora UFPR.

Oliveira, J. P. (2010). Efeitos de um programa de intervenção metatextual em escolares com dificuldades de aprendizagem. Tese de Doutorado, Universidade Estadual Paulista, Faculdade de Filosofia e Ciências, Marília.

Pinheiro, R.; Leitão, S. (2007). Consciência da "Estrutura Argumentativa" e produção textual. Psicologia: Teoria e Pesquisa, 23(4), 423-432.

Ribeiro, C. (2003). Metacognição: um apoio ao processo de aprendizagem. Psicologia: Reflexão e Crítica, 16(1), 109-116.

Rodrigues, M. R. F.; Vilela, F. C. (2012). Resolução da situaçãoproblema e desfecho em histórias de crianças de 7 e 9 anos. Psicologia: Ciência e Profissão, 32(2), 422-437.

Salles, J. F.; Correa, J. (2014). A produção escrita de histórias por crianças e sua relação com as habilidades de leitura e escrita de palavras/pseudopalavras. Psicologia USP, 25(2), 189-200.

Santos, M. J.; Barrera, S. D. (2015). Escrita de textos narrativos sob diferentes condições de produção. Psicologia Escolar e Educacional,19(2), 253-260. http://dx.doi.org/10.1590/01044060.48026

Silva, T. F.; Guimarães, S. R. K. (2017). Habilidades metatextuais: revendo evidências de pesquisas brasileiras. In: Maluf, M. R.; Santos, M. J. (Orgs.), Ensinar a ler: das primeiras letras à leitura fluente (pp. 117-144). Curitiba: CRV.

Spinillo, A. G.; Martins, R. A. (1997). Uma análise da produção de histórias coerentes por criança. Psicologia: Reflexão e Crítica, 10(2), 219-248.

Spinillo, A. G. (2009). A consciência metatextual. In: Mota, M. (Org.), Desenvolvimento Metalinguístico: questões contemporâneas (pp.77-113). São Paulo: Casa do Psicólogo.
Recebido em: 27 de março de 2017 Aceito em: 07 de novembro de 2017

Apoio financeiro do Conselho Nacional de Desenvolvimento Científico e Tecnológico (CNPq). Trabalho derivado de tese. 